\title{
Dipole Moments and Polarizabilities of Benzophenones Estimated from Spectroscopic Measurements *
}

\author{
M. Stoń \\ Institute of Physics, Pedagogical High School, Słupsk, Poland \\ Z. Naturforsch. 36a, 909-912 (1981); received May 25, 1981
}

\begin{abstract}
The effect of microenvironment on the absorption spectra of benzophenone and its aminoderivatives in $n$-heptane/n-butanol and $n$-heptane/benzene mixtures was investigated. The local dielectic constants, the composition of the solvatation shell, the Onsager cavity radius " $a$ " and the values of $\alpha / a^{3}$ ( $\alpha$ - the polarizability of solute molecules) have been evaluated from the spectral shifts.
\end{abstract}

The electric and optical properties of molecules are commonly investigated by measurements of their absorption and fluorescence spectra, both in pure solvents of different polarities [1] and in mixed solvents [2]. The molecules benzophenone (BF), 2-aminobenzophenone ( $2 \mathrm{ABF})$ and 4-aminobenzophenone $(4 \mathrm{ABF})$ investigated in this paper show no fluorescence at room temperature. Their absorption spectra, however, are shifted depending on the polarity of the solvent. Figure 1 shows the maxima of the absorption bands as functions of the content of n-butyl alcohol in $n$-heptane. In the case of benzophenone ( $n \rightarrow \pi^{*}$ transition) an increase in the solvent polarity results in a shift of the spectrum to the short-wave side, whereas the absorption spectra of 2 -aminobenzophenone and 4-aminobenzophenone $(\pi \rightarrow \pi *$ transitions) are shifted to the longwave side. Therefore measurements of absorption spectra in mixtures of polar and nonpolar solvents were carried out to determine the composition of the first coordination solvent shell, the Onsager cavity radius and the mean energy of interaction between the solvent and solute molecules in the ground state.

The absorption spectra at $293 \mathrm{~K}$ were measured using a Zeiss Specord UV VIS spectrofotometer. The refraction indices of solutions at $293 \mathrm{~K}$ were determined by means of an Abbe refractometer.

\section{Solvent Shells}

We assume, according to $[3,4]$, that the molecular radii and the refraction indices of solvents are

* This work was carried out under the project MR.I.5.2. Reprint requests to Dr. Marian Stoń, Zakład Fizyki, Wyższa Szkoła Pedagogiczna, ul. Arciszewskiego 22 B, 76200 Słupsk, Poland. equal $\left(a_{\mathrm{s}}^{\mathrm{I}}=a_{\mathrm{s}}^{\mathrm{II}}=a_{\mathrm{S}}\right.$ and $\left.n_{\mathrm{I}}=n_{\mathrm{II}}=n\right)$. The indices I and II refer to nonpolar (n-heptane) and polar (n-butanol) solvents, respectively. The mean fillingup degree of the solvent shell with molecules of the polar solvent in the first coordination sphere is de-

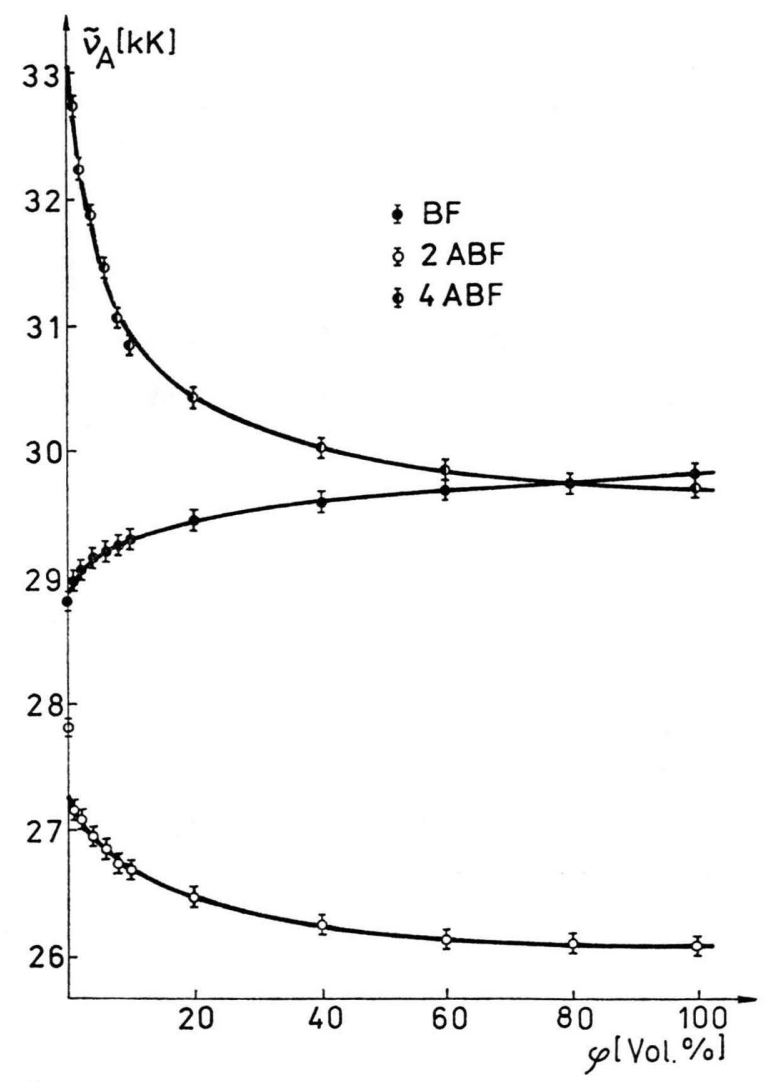

Fig. 1. Maxima of the absorption bands of BF, $2 \mathrm{ABF}$ and $4 \mathrm{ABF}$ as functions of content ( in per cent) of n-butyl alcohol in n-heptane.

0340-4811 / 81 / 0800-0909 \$01.00/0. - 'Please order a reprint rather than making your own copy. 
fined as

$$
\gamma \equiv\left\langle\gamma_{\mathrm{II}}\right\rangle=\frac{z_{\mathrm{I}}}{z_{\mathrm{I}}+z_{\mathrm{II}}},
$$

where $z_{\mathrm{I}}$ and $z_{\mathrm{II}}$ are the numbers of molecules of nonpolar and polar solvent in the solvent shell, respectively.

The shift of the absorption spectra in a binary solvent is $[3,5]$

$$
\begin{aligned}
\delta \tilde{\nu}_{\mathrm{A}} & =\tilde{\nu}_{\mathrm{A}}-\tilde{\nu}_{\mathrm{A}}^{\mathrm{I}} \\
& =-C_{\mathrm{A}}\left(\frac{2 n^{2}+1}{n^{2}+2}\right)\left(\frac{\left\langle\varepsilon_{1}\right\rangle-1}{\left\langle\varepsilon_{1}\right\rangle+2}-\frac{n^{2}-1}{n^{2}+2}\right),
\end{aligned}
$$

where $\tilde{\nu}_{\mathrm{A}}$ is the wave number maximum of the absorption band for the mixed solvent and $\tilde{\nu}_{\mathrm{A}}^{\mathrm{I}}$ for the nonpolar solvent, and $C_{\mathrm{A}}=\frac{1}{2}\left(m_{2}-m_{1}\right)$. The parameters $m_{1}$ and $m_{2}$ are connected with the dipole moments of the solute molecules in the ground and excited states (see [1]). In this work the values of $C_{\mathrm{A}}$ for $\mathrm{BF}, 2 \mathrm{ABF}$ and $4 \mathrm{ABF}$ were experimentally obtained using the theory of Kawski and Bilot [1]. From (2) we obtain values of $\left\langle\varepsilon_{1}\right\rangle$ [9]:

$$
\left\langle\varepsilon_{1}\right\rangle=\frac{n^{2}-2 \Delta \tilde{\nu}_{\mathrm{A}}}{1+\Delta \tilde{v}_{\mathrm{A}}},
$$

where

$$
\Delta \tilde{v}_{\mathrm{A}}=\frac{\delta \tilde{v}_{\mathrm{A}}}{C_{\mathrm{A}}} \frac{\left(n^{2}+2\right)^{2}}{3\left(2 n^{2}+1\right)} .
$$

For the mixed solvents, it was assumed [5] that the local dielectric constant $\left\langle\varepsilon_{1}\right\rangle$ of the solvent shell is defined by the following dependence between the dielectric constant of the nonpolar $\left(\varepsilon_{\mathrm{I}}\right)$ and polar $\left(\varepsilon_{\text {II }}\right)$ solvents :

$$
\left\langle\varepsilon_{\mathrm{I}}\right\rangle \approx \varepsilon_{\mathrm{I}} \gamma_{\mathrm{I}}+\varepsilon_{\mathrm{II}} \gamma_{\mathrm{II}} .
$$

From (1) and (5) follows

$$
\gamma=\frac{\left\langle\varepsilon_{\mathrm{l}}\right\rangle-\varepsilon_{\mathrm{I}}}{\varepsilon_{\mathrm{II}}-\varepsilon_{\mathrm{I}}} .
$$

The values of $\left\langle\varepsilon_{1}\right\rangle$ and $\gamma$ calculated from (3) and (6) are given in Table $I$.

\section{Determination of the Onsager Cavity Radius}

The Onsager cavity radius " $a$ " of the solute molecule can be determined from absorption spectra measured in mixtures of polar and nonpolar solvents. According to Gorodyskii and Bakhshiev [2] the value " $a$ " of the absorbing molecule can be determined from the relative absorption shift

$$
\Delta \tilde{\nu}_{\mathbf{A}}^{\mathrm{rel}}=\frac{\tilde{\nu}_{\mathbf{A}}^{\mathrm{I}}-\tilde{\nu}_{\mathrm{A}}}{\tilde{\nu}_{\mathrm{A}}^{\mathrm{I}}-\tilde{\nu}_{\mathbf{A}}^{\mathrm{II}}}=\frac{x}{(1-x) \exp (-B)+x},
$$

where $x$ is the mole fraction of the polar solvent in nonpolar/polar mixtures

$$
\begin{aligned}
B= & \frac{\mu_{\mathrm{g}}^{2}}{a^{3}} \frac{C_{\mathrm{II}}-C_{\mathrm{I}}}{k T}-l \frac{\left\langle\mu_{\mathrm{s}}^{\mathrm{II}}\right\rangle^{2}}{a_{\mathrm{s}}^{3}} \frac{C_{\mathrm{II}}}{k T} \\
& +l \frac{\left\langle\mu_{\mathrm{s}}^{\mathrm{I}}\right\rangle^{2}}{a_{\mathrm{s}}^{3}} \frac{C_{\mathrm{I}}}{k T}
\end{aligned}
$$

\begin{tabular}{|c|c|c|c|c|c|c|c|c|c|c|}
\hline \multirow[t]{2}{*}{$\varphi[\%]$} & \multirow[t]{2}{*}{$\varepsilon[4]$} & \multicolumn{3}{|c|}{ Benzenophenone $[\mathrm{BF}]$} & \multicolumn{3}{|c|}{$\begin{array}{l}\text { 2-Aminobenzenophenone } \\
{[2 \mathrm{ABF}]}\end{array}$} & \multicolumn{3}{|c|}{$\begin{array}{l}\text { 4-Aminobenzenophenone } \\
{[4 \mathrm{ABF}]}\end{array}$} \\
\hline & & $\Delta \tilde{v}_{\mathrm{A}}^{\mathrm{rel}}$ & $\left\langle\varepsilon_{1}\right\rangle$ & $\gamma[\%]$ & $\Delta \tilde{v}_{\mathrm{A}}^{\mathrm{rel}}$ & $\left\langle\varepsilon_{1}\right\rangle$ & $\gamma[\%]$ & $\Delta \tilde{v}_{\mathrm{A}}^{\mathrm{rel}}$ & $\left\langle\varepsilon_{1}\right\rangle$ & $\gamma[\%]$ \\
\hline 0 & 1.918 & 0.0000 & 1.918 & 0.00 & 0.0000 & 1.918 & 0.00 & 0.0000 & 1.918 & 0.00 \\
\hline 1 & 1.962 & 0.1224 & 2.610 & 4.36 & 0.0833 & 2.220 & 1.90 & 0.0898 & 2.237 & 2.01 \\
\hline 2 & 1.970 & 0.2653 & 2.993 & 6.78 & 0.1499 & 2.468 & 3.47 & 0.2275 & 2.808 & 5.61 \\
\hline 4 & 2.008 & 0.3469 & 3.445 & 9.63 & 0.2500 & 2.915 & 6.29 & 0.3593 & 3.520 & 10.10 \\
\hline 6 & 2.063 & 0.3980 & 3.773 & 11.69 & 0.3500 & 3.462 & 9.74 & 0.4730 & 4.329 & 15.20 \\
\hline 8 & 2.128 & 0.4592 & 4.220 & 14.51 & 0.4417 & 4.083 & 13.65 & 0.5988 & 5.555 & 22.93 \\
\hline 10 & 2.198 & 0.5102 & 4.650 & 17.23 & 0.4750 & 4.345 & 15.30 & 0.6557 & 6.278 & 27.50 \\
\hline 20 & 2.698 & 0.6429 & 6.108 & 26.42 & 0.6667 & 6.434 & 28.48 & 0.7844 & 8.574 & 41.97 \\
\hline 40 & 5.170 & 0.8163 & 9.002 & 44.80 & 0.8499 & 10.268 & 52.65 & 0.9072 & 12.375 & 65.94 \\
\hline 60 & 8.980 & 0.8979 & 12.019 & 63.37 & 0.9417 & 13.983 & 76.08 & 0.9581 & 14.892 & 81.81 \\
\hline 80 & 13.550 & 0.9592 & 14.987 & 82.41 & 0.9666 & 15.401 & 85.02 & 0.9850 & 16.622 & 92.72 \\
\hline 100 & 17.750 & 1.0000 & 17.750 & 100.00 & 1.0000 & 17.750 & 100.00 & 1.0000 & 17.750 & 100.00 \\
\hline
\end{tabular}

contains the Onsager radius $a$.

The constants

$$
C_{\mathrm{I}, \mathrm{II}}=\frac{\varepsilon_{\mathrm{I}, \mathrm{II}}-1}{\varepsilon_{\mathrm{I}, \mathrm{II}}+2},
$$

$\mu_{\mathrm{g}}$, the ground-state dipole moment of the solute, $\left\langle\mu_{\mathrm{s}}^{\mathrm{I}}\right\rangle$ and $\left\langle\mu_{\mathrm{s}}^{\mathrm{II}}\right\rangle$, the average dipole moments of the solvent molecules I and II (for their determination

Table 1. 


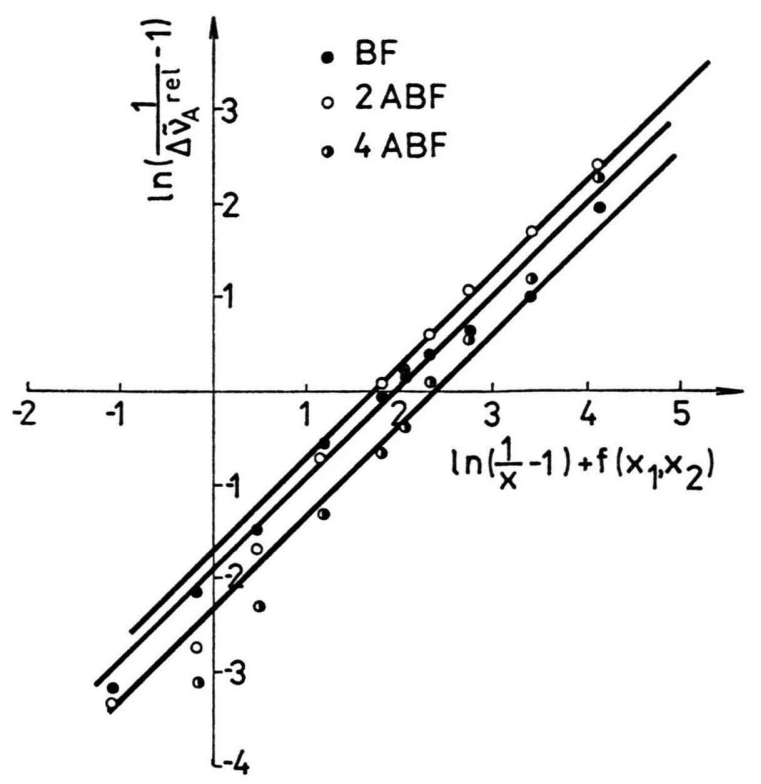
Fig. 2. $\ln \left(\frac{1}{\Delta \tilde{v}_{\mathrm{A}}^{\text {re1 }}}-1\right)$ vs. $\ln \left(\frac{1}{x}-1\right)+f\left(x_{1}, x_{2}\right)$, accord-
ing (7).

see [2]), and $l$, an empirical parameter $(l \approx 1)$, have known values.

Plotting $\ln \left(1 / \Delta \tilde{\nu}_{\mathrm{A}}^{\mathrm{rel}}-1\right)$ vs.

$$
\ln \left(\frac{1}{x}-1\right)+l \frac{\left\langle\mu_{\mathrm{s}}^{\mathrm{II}}\right\rangle^{2}}{a_{\mathrm{s}}^{3}} \frac{C_{\mathrm{II}}}{k T}-l \frac{\left\langle\mu_{\mathrm{s}}^{\mathrm{I}}\right\rangle^{2}}{a_{\mathrm{s}}^{3}} \frac{C_{\mathrm{I}}}{k T},
$$

according to (7) the value $\frac{\mu_{\mathrm{g}}^{2}}{a^{3}} \frac{C_{\mathrm{II}}-C_{\mathrm{I}}}{k T}$ can easily be found. Figure 2, where

$$
f\left(x_{1}, x_{2}\right) \equiv \frac{l}{a_{\mathrm{s}}^{3} k T}\left(\left\langle\mu_{\mathrm{s}}^{\mathrm{II}}\right\rangle^{2} C_{\mathrm{II}}-\left\langle\mu_{\mathrm{s}}^{\mathrm{I}}\right\rangle^{2} C_{\mathrm{I}}\right),
$$

shows this dependence for $\mathrm{BF}, 2 \mathrm{ABF}$ and $4 \mathrm{ABF}$. Hence we obtained values of $\frac{\mu_{\mathrm{g}}^{2}}{a^{3}} \frac{C_{\mathrm{II}}-C_{\mathrm{I}}}{k T}$ for these molecules, and using known $\mu_{\mathrm{g}}$ values it was possible to determine the Onsager cavity radii [6] (Table II).

\section{Determination of $\alpha / a^{3}$}

According to the theory of Schuyer [7] and Bakhshiev [8] the values of $\alpha / a^{3}$ for absorbing molecules can be determined. This requires the measurement of the integrated absorption spectra of the molecules studied in the mixtures of two nonpolar solvents with different refractive indices. In this case
Table 2.

\begin{tabular}{lllll}
\hline Substance & $\mu_{\mathrm{g}}[\mathrm{D}]$ & $a[\AA]$ & $\alpha / a^{3}$ & $-\Delta F_{\mathrm{m}}\left[\mathrm{cm}^{-1}\right]$ \\
\hline $\mathrm{BF}$ & $2.98[12]$ & 4.04 & 0.46 & 52 \\
$2 \mathrm{ABF}$ & $2.65^{*}$ & 4.00 & 0.55 & 21 \\
$4 \mathrm{ABF}$ & $4.73^{2}[13]$ & 5.16 & 0.75 & 128 \\
\hline
\end{tabular}

* The dipole moment $\mu_{\mathrm{g}}$ for 2-Aminobenzenophenone calculated by vectorial summation of $\mu_{\mathrm{g}}$ of benzenophenone and $\mu$ of the substituted group [14].

we have

$$
\left(g \frac{\int K_{\nu} \mathrm{d} v}{\int K_{\nu}^{0} \mathrm{~d} \nu}\right)^{-1 / 2}=A^{-1 / 2}\left(1-\frac{2 \alpha}{a^{3}} \frac{n^{2}-1}{2 n^{2}+1}\right),
$$

where

$g=\frac{\left(2 n^{2}+1\right)^{2}}{9 n^{3}}$ and $A=\frac{f \pi e^{2}}{3 m_{\mathrm{c}} \int K_{v}^{0} \mathrm{~d} v}$.

$K_{v}$ is the molar extinction coefficient of the solute molecules in the solvent mixture, $K_{v}^{0}$ refers to the solvent with the highest refractive index $n$. $e$ is electric charge, $m$ the mass of an electron, $c$ the velocity of light in vacuum and $f$ the oscillator strength. Plotting $\left(g \int K_{\nu} \mathrm{d} v / \int K_{v}^{0} \mathrm{~d} v\right)^{-1 / 2}$ as a function of $\left(2 n^{2}-2\right) /\left(2 n^{2}+1\right)$ (for the mixture) we obtain a straight line which cuts the ordinate axis at a point $A^{-1 / 2}$ and the slope of which is $\alpha / a^{3} A^{-1 / 2}$ [9]. Figure 3 shows the curves plotted according to (10) for $\mathrm{BF}, 2 \mathrm{ABF}$ and $4 \mathrm{ABF}$. The values of $\alpha / a^{3}$ obtained from these curves are given in Table II. It seems possible that the high value of $\alpha / a^{3}$ for $4 \mathrm{ABF}$ molecules (highest dipole moment in the

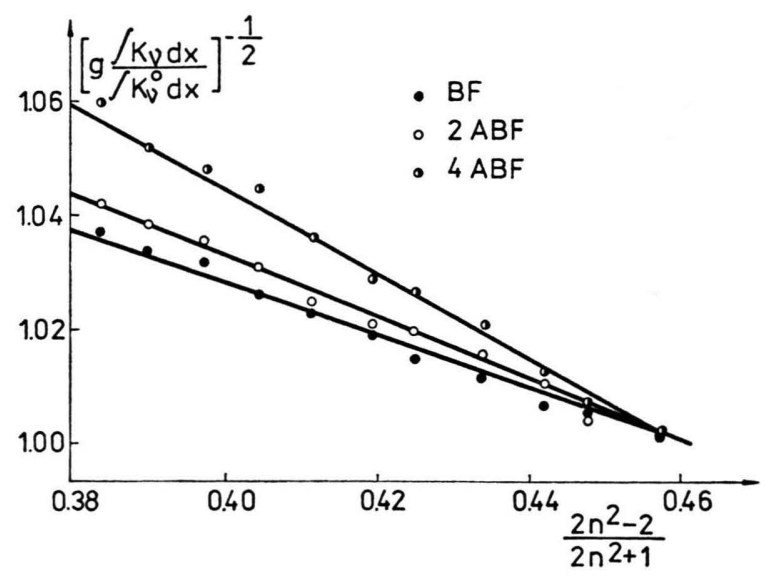

Fig. 3. $\left(g \int K_{v} \mathrm{~d} v / \int K_{\nu} 0 \mathrm{~d} v\right)^{-1 / 2}$ as a function of $\left(2 n^{2}-2\right) /$ $\left(2 n^{2}+1\right)$ for benzophenones in mixtures of $n$-heptane and benzene. 
ground state) results from the difference between the dielectric constants of $n$-heptane and benzene.

\section{Mean Energy of Interaction}

The statistical model of Masurenko [10] for ternary solvents was applied to determine the mean energy of interaction between the solute molecules and the binary solvent. The relative filling-up degree $\gamma \equiv \theta$ [9] of the solvent shell with the molecules of the polar solvent is given by

$$
\frac{\gamma}{1-\gamma}=\frac{x}{1-x} \exp \left(-\frac{\Delta F_{\mathrm{m}}}{k T}\right) \text {. }
$$

$\gamma$ is related to the spectroscopics quantities by the expression

$$
\gamma=\frac{\left(n^{2}+2\right)}{\left(\varepsilon_{\mathrm{II}}-\varepsilon_{\mathrm{I}}\right)\left[\frac{1}{\Delta \tilde{\nu}_{\mathrm{A}}}-1\right]} .
$$

(12) was obtained [11] by taking into account the polarizability of the solute molecule. Plotting $\ln [\gamma /(1-\gamma)]$ vs. $\ln [x /(1-x)]$ (Fig. 4) we obtain straight lines the slopes of which are 1 . On the ordinate axis they cut a segment corresponding to the energy of interaction $-\Delta F_{\mathrm{m}}$. The energies of

[1] L. Bilot and A. Kawski, Z. Naturforsch. 17a, 621 (1962); 18 a, 10, 256 (1963).

[2] V. A. Gorodyskii and N. G. Bakhshiev, Opt. Spektr. 31, 218 (1971).

[3] N. G. Bakhshiev, V. P. Volkov, and A. V. Altaiskaia, Opt. Spektr. 28, 51 (1970).

[4] A. Kawski and C. Strzałkowska, Z. Naturforsch. 27 a, 916 (1972).

[5] A. Kawski and J. Czajko, Z. Naturforsch. 29a, 84 (1974).

[6] A. Kawski, I. Gryczyński, and M. Stoń, Bull. Acad. Polon. Sci: Ser. Sci. Math. Astronom. Phys. 23, 1125 (1975).

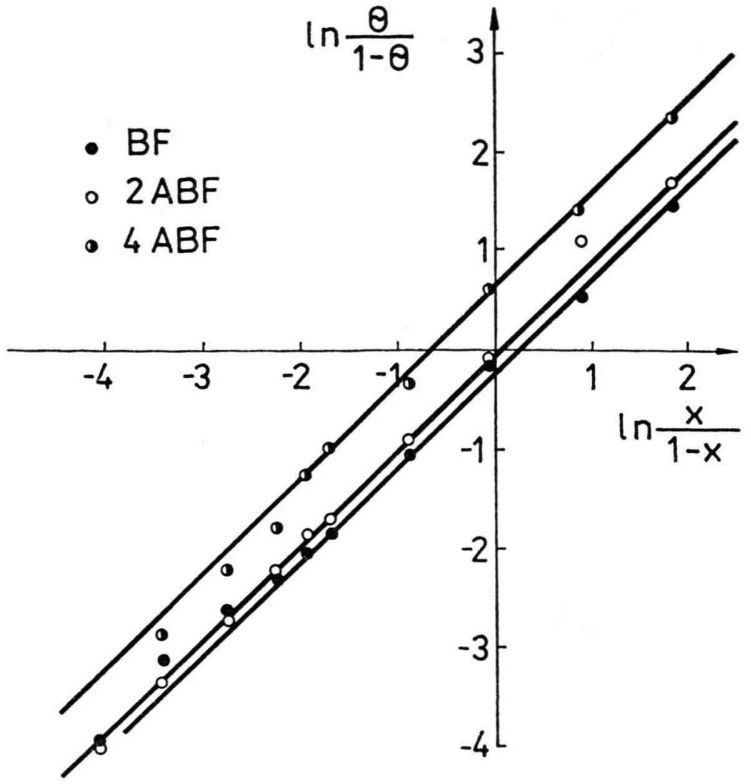
Fig. 4. Plott of $\ln \frac{\theta}{1-\theta}$ vs. $\ln \frac{x}{1-x}$ for benzophenones,
see (11).

interaction between molecules of $\mathrm{BF}, 2 \mathrm{ABF}, 4 \mathrm{ABF}$ and the solvent are given in Table 2

I thank Professor A. Kawski, University of Gdańsk, for his valuable remarks.

[7] J. Schuyer, Rec. Trav. Chim. 72, 933 (1953).

[8] N. G. Bakhshiev, Opt. Spektr. 5, 646 (1958).

[9] I. Gryczyński and H. Szmaciński, Acta Phys. Polon. A55, 251 (1979).

[10] J. T. Masurenko, Opt. Spektr. 33, 1060 (1972).

[11] A. Kawski, J. Czajko, and M. Ahrens. Acta Phys. Polon. A45, 625 (1974).

[12] R. M. Hochstrasser and L. J. Noe, J. Mol. Spektr. 38, 175 (1971).

[13] H. Janiszewski, L. Stefaniak, T. Urbański, and M. Witanowski, Roczniki Chemii, 44, 2361 (1970).

[14] O. Exner, Dipole Moments in Organic Chemistry, Stuttgart 1975. 